\title{
Pigmented Lesions of Skin: A Histopathologic Experience at a Tertiary Care Center in Central Nepal
}

\author{
Binita Goyal,' Suman Rai, 'Mamata Sedhain,' Pratigya Subedi' \\ 'Department of Pathology, College of Medical Sciences, Bharatpur, Chitwan, Nepal.
}

\begin{abstract}
Introduction

Pigmented skin lesions refer to lesions that are brown, black or blue in color. These are not always melanocytic in origin. Keratinocytic, vascular or reactive pigmentation in other lesions can also appear pigmented. The main aim of the study was to see the histopathological spectrum and objective was to compare clinical and histopathological diagnoses in pigmented skin lesions.
\end{abstract}

\section{Methods}

This descriptive study was carried out on 43 pigmented skin lesions that were biopsied over a 1 and half year period from Jan 2018 to June 2019 in College of Medical Sciences and Teaching Hospital.

\section{Results}

Age of the patient ranged from 10 to 88 years and mean \pm SD was $42.02 \pm 19.73$ years. There were $21(48.8 \%)$ males and $22(51.2 \%)$ females with a male female ratio 0.9:1. Melanocytic nevus was the most common histopathological diagnosis (11 cases, 25.6\%). Reactive pigmentation was seen in $20(46.5 \%)$ cases. Malignant cases comprised $6(14.0 \%)$ cases which included $2(4.7 \%)$ cases of melanoma, $2(4.7 \%)$ cases of pigmented basal cell carcinoma and $1(2.3 \%)$ case each of basaloid squamous cell carcinoma and trichoblastic carcinoma each. Clinicopathological agreement could be seen in $32(74.4 \%)$ cases. However, malignancy was clinically suspected in only half of histologically diagnosed cases.

\section{Conclusion}

Melanocytic nevi were the most common pigmented lesions diagnosed. Not all pigmented lesions are melanocytic in origin. Malignant tumors can sometimes appear deceptively benign and also tumors other than melanoma can be pigmented. Hence, histopathological examination remains the gold standard in diagnosing these conditions and guiding appropriate management.

Keywords: melanocytic; melanoma; nevus; pigmented

Correspondence: Dr. Binita Goyal, Department of Pathology, College of Medical Sciences, Bharatpur, Chitwan, Nepal. Email:binitagoyal@yahoo.com. Phone: +977-9860167741. 


\section{INTRODUCTION}

Skin is a protective interface between potentially dangerous external environment and vulnerable internal organs. Pigmented skin lesions refer to lesions that are brown, black or blue in color. ${ }^{1}$ These are one of the most frequently encountered causes for dermatologic consultation. ${ }^{2}$

The differential diagnoses for these pigmented lesions may be melanocytic lesions, keratinocytic lesions, vascular lesions or reactive pigmentation in other conditions. ${ }^{1}$

Majority of these conditions are benign and only a small minority are melanoma. ${ }^{3}$ Still, many of them can mimic clinically as melanocytic lesions including melanoma. Hence, histopathological interpretation is important in diagnosis of these conditions. ${ }^{4}$ The purpose of histopathological examination is not only to give accurate diagnosis, but also to rule out malignant tumors, assess completeness of excision of surgical margins and diagnose atypical conditions like dysplastic nevus which is a potential precursor for development of malignant melanoma. ${ }^{5}$

Hence, this study was designed to see the histopathological pattern of pigmented lesions of skin and also to compare clinical diagnosis and histopathological diagnosis which would further aid in patient management.

\section{METHODS}

This descriptive study was carried out on all the clinically pigmented skin lesions that were biopsied over a 1 and half year period from Jan 2018 to June 2019 in Department of Pathology in College of Medical Sciences and Teaching Hospital which is a tertiary care hospital in central region of Nepal. Ethical clearance was obtained from institutional review committee (Reference no: 2020-032). Patient particulars, presenting complaints, site of the lesion, its duration, other clinical details and clinical diagnosis were noted from the records. The histology slides were stained with haematoxylin and eosin (H and E) stain. Pigmented skin lesions which were histologically reported during the study period were reviewed and analyzed according to age, gender, number, type of lesion, site of occurrence and histological type. All the clinically pigmented skin lesions were included in the study. Unsatisfactory biopsies and in cases in which definite histopathological diagnoses could not be given, were excluded. Data was initially entered in MS-Excel, refined and finally analyzed by SPSS 16.0. Results were expressed as frequencies and percentages. Comparison between clinical and histopathological diagnosis was expressed as percentage.

\section{RESULTS}

A total of 43 cases of histologically diagnosed pigmented skin lesions were reviewed during the study period. Age of the patient ranged from 10 to 88 years and mean \pm SD was $42.02 \pm 19.73$ years. There were $21(48.8 \%)$ males and 22 $(51.2 \%)$ females with a male female ratio 0.9:1 (Table 1).

\begin{tabular}{|l|l|l|l|}
\hline \multicolumn{4}{|c|}{ Table 1. Age and sex of the patients. $(\mathrm{n}=43)$} \\
\hline $\begin{array}{c}\text { Age group } \\
\text { (years) }\end{array}$ & $\begin{array}{c}\text { Male } \mathbf{n} \\
(\%)\end{array}$ & $\begin{array}{c}\text { Female } \mathbf{n} \\
(\%)\end{array}$ & $\begin{array}{c}\text { Total } \mathbf{n} \\
(\%)\end{array}$ \\
\hline $0-20$ & $3(7.0)$ & $3(7.0)$ & $6(13.6)$ \\
\hline $21-40$ & $9(20.9)$ & $8(18.6)$ & $17(39.5)$ \\
\hline $41-60$ & $7(16.3)$ & $5(11.6)$ & $12(27.9)$ \\
\hline $61-80$ & $2(4.7)$ & $5(11.6)$ & $7(16.3)$ \\
\hline$>80$ & 0 & $1(2.3)$ & $1(2.3)$ \\
\hline Total & $21(48.8)$ & $22(51.2)$ & $43(100)$ \\
\hline
\end{tabular}

Most common site were extremities in 15 (34.9\%) cases followed by face in $14(32.6 \%)$, trunk in $6(14.0 \%)$ cases, scalp in $5(11.6 \%)$ cases and multiple sites in $3(7.0 \%)$ cases. The lesions were solitary in $29(67.4 \%)$ cases and multiple in 14 $(32.6 \%)$ cases. Most common type of lesions were nodules in 18 (41.9\%) cases, followed by 
plaques in $16(37.2 \%)$ cases, patch in $4(9.3 \%)$ cases, papule in $3(7.0 \%)$ cases and macule in 2 $(4.7 \%)$ cases.

The most common clinical diagnosis was melanocytic nevus in $14(32.6 \%)$ cases. Clinical diagnoses are presented in Table 2. highest number of 20 (46.5\%) cases. However, the individual histopathological diagnoses were much varied in the latter group (Table 3). Overall, malignant cases comprised $6(14.0 \%)$ cases which included $2(4.7 \%)$ cases of melanoma, 2 $(4.7 \%)$ cases of pigmented basal cell carcinoma

Table 2. Clinical diagnoses of the pigmented skin lesions. $(n=43)$

\begin{tabular}{|l|l|l|l|}
\hline S.N. & Clinical diagnosis & No. of cases $(\mathbf{n})$ & Percent $(\%)$ \\
\hline 1. & Melanocytic nevus & 14 & 32.6 \\
\hline 2. & Discoid Lupus Erythematosus (DLE) & 4 & 9.3 \\
\hline 3. & Lichen planus & 3 & 7.0 \\
\hline 4. & Lichen planus hypertrophicus (LPH) & 3 & 7.0 \\
\hline 5. & Hemangioma & 2 & 4.7 \\
\hline 6. & Seborrhoeic keratosis & 2 & 4.7 \\
\hline 7. & Lichen planus pigmentosus (LPP) & 2 & 4.7 \\
\hline 8. & Others* & 13 & 30.2 \\
\hline
\end{tabular}

Others*: $1(2.3 \%)$ case each of blue nevus, nevus of Ota, pigmented verrucous nevus (PVC), melanoma, basal cell carcinoma (BCC), appendageal tumor, dermatofibroma, lichen amyloidosis, lichen simplex chronicus (LSC), morphea, pemphigus foliaceus, stasis dermatitis and leprosy.

Melanocytic nevus was the most common histopathological diagnosis seen in $11(25.6 \%)$ cases. Melanocytic lesions comprised 15 (34.9\%) cases. Reactive pigmentation was seen in and $1(2.3 \%)$ case each of basaloid squamous cell carcinoma and trichoblastic carcinoma each. All the malignant cases were solitary and most of them presented as nodules and only 1 case presented as plaque.

Table 3. Histopathological diagnoses of pigmented skin lesions. $(n=43)$

\begin{tabular}{|l|l|l|l|}
\hline S.N. & Histopathological diagnosis & No. of cases (n) & Percent (\%) \\
\hline
\end{tabular}

Melanocytic lesions $(n=15,34.9 \%)$

\begin{tabular}{|l|l|l|l|}
\hline 1. & Melanocytic nevus (Fig 1) & 11 & 25.6 \\
\hline 2. & Nevus of Ota (Fig 2) & 1 & 2.3 \\
\hline 3. & Melanoma (Figs 3, 4) & 2 & 4.7 \\
\hline 4. & Oral melanosis & 1 & 2.3 \\
\hline
\end{tabular}

Keratinocytic lesions $(n=7,16.3 \%)$

\begin{tabular}{|l|l|l|l|}
\hline 5. & Pigmented verrucous nevus (Fig 5) & 1 & 2.3 \\
\hline 6. & Pigmented basal cell carcinoma (pigmented BCC) (Fig 6) & 2 & 4.7 \\
\hline 7. & Trichoblastic carcinoma (Fig 7) & 1 & 2.3 \\
\hline 8. & Basaloid squamous cell carcinoma (Basaloid SCC) (Fig 8) & 1 & 2.3 \\
\hline 9. & Seborrhoeic keratosis (Fig 9) & 2 & 4.7 \\
\hline
\end{tabular}




\begin{tabular}{|l|l|l|l|}
\hline \multicolumn{2}{|l|}{ Vascular lesions $(\mathbf{n}=\mathbf{1}, \mathbf{2 . 3} \%)$} & \multicolumn{2}{l|}{} \\
\hline 10. & Hemangioma & 1 & 2.3 \\
\hline Reactive pigmentation in other conditions $(\mathbf{n}=\mathbf{2 0}, \mathbf{4 6 . 5} \%)$ & 1 & 2.3 \\
\hline 11. & Neurofibroma & 1 & 4.7 \\
\hline 12. & Dermatofibroma & 2 & 7.0 \\
\hline 13. & Lichen planus & 3 & 4.7 \\
\hline 14. & Lichen planus pigmentosus & 2 & 7.0 \\
\hline 15. & Lichen planus hypertrophicus (Fig 10) & 3 & 2.3 \\
\hline 16. & Lichen simplex chronicus & 3 & 11.6 \\
\hline 17. & Discoid lupus erythematosus & 1 & 2.3 \\
\hline 18. & Morphea & 5 & 2.3 \\
\hline 19. & Stasis dermatitis & 1 & 2.3 \\
\hline 20. & Leprosy & 1 & 100 \\
\hline & Total & 1 & $\mathbf{1}$ \\
\hline
\end{tabular}

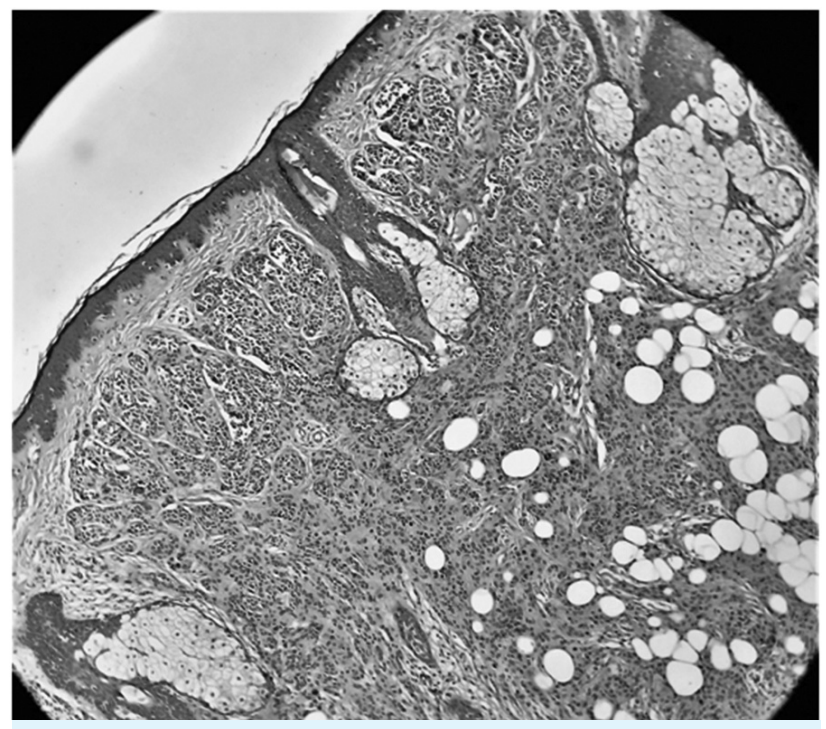

Figure 1. Intradermal nevus- nevus cells are more dyscohesive and spindly in the deeper areas (H and E X100)

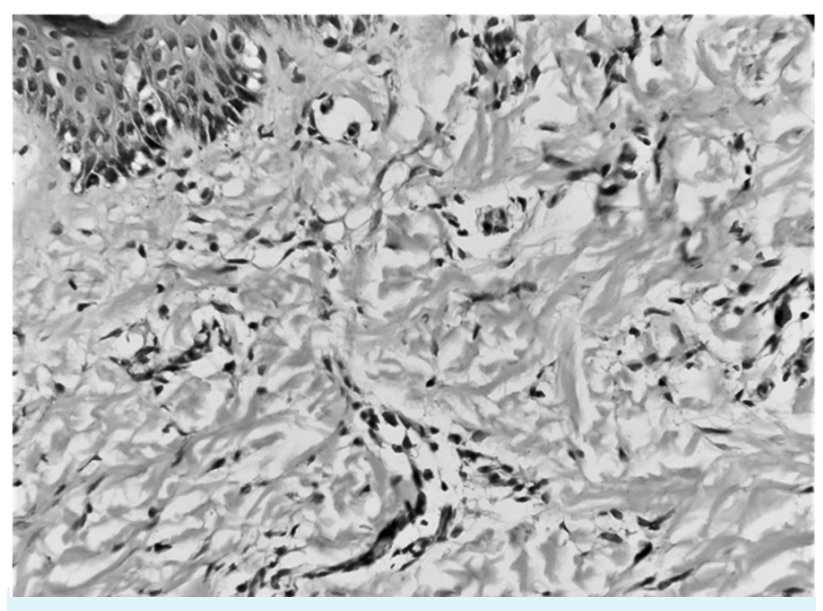

Figure 2. Dendritic melanocytes within dermis in Nevus of Ota ( $\mathrm{H}$ and $\mathrm{E} \mathrm{X} 400$ )

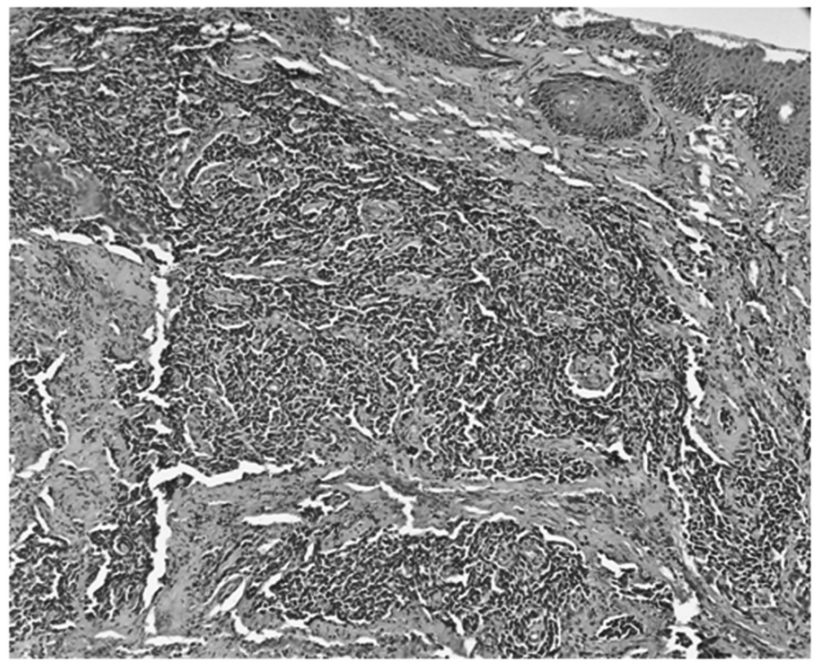

Figure 3. Melanoma (H and E X100)

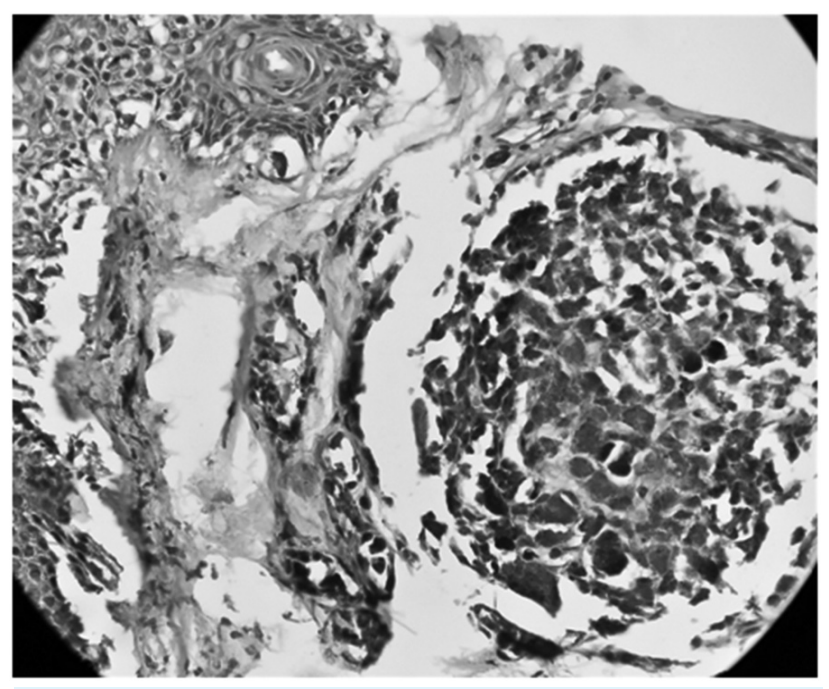

Figure 4. Melanoma ( $\mathrm{H}$ and $\mathrm{E} X 400)$ 


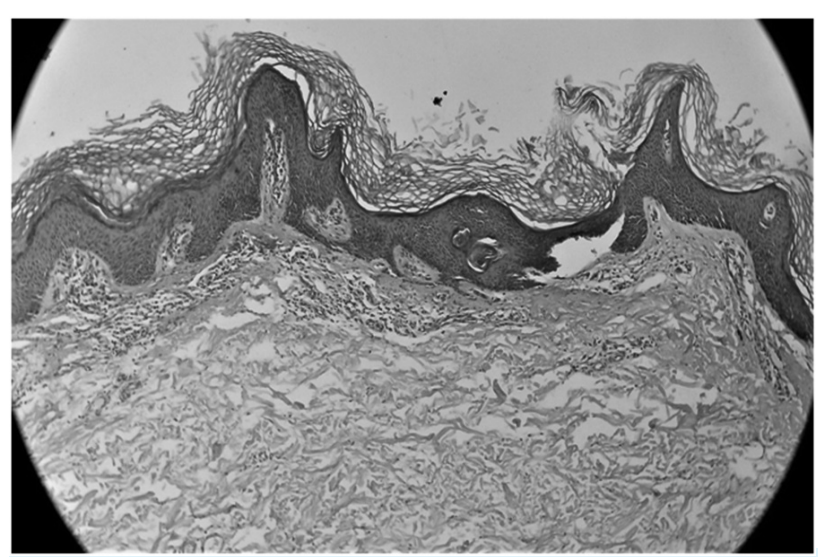

Figure 5. Epidermal verrucous nevus ( $\mathrm{H}$ and $\mathrm{E} \times 100)$

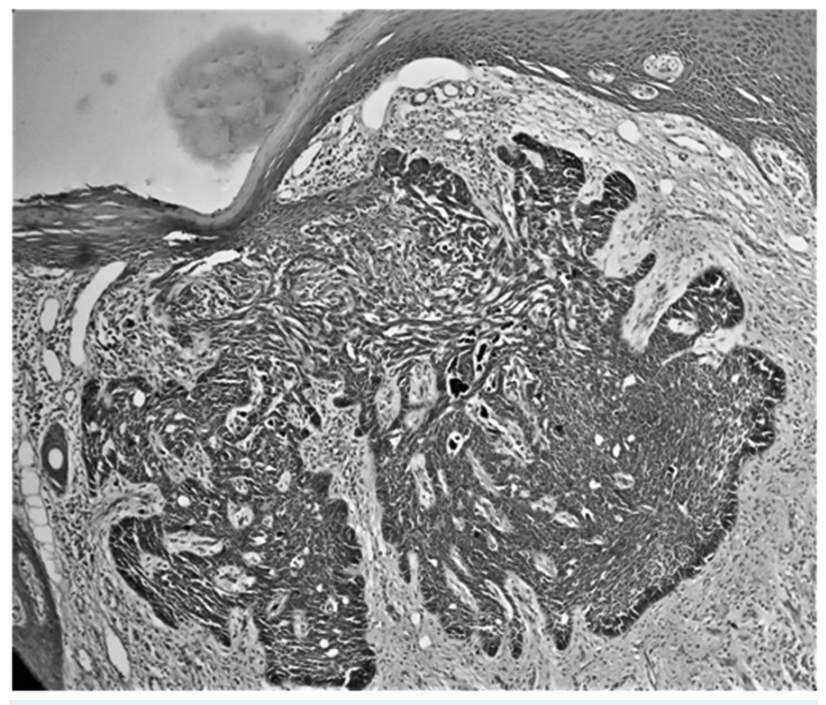

Figure 6. Pigmented basal cell carcinoma (H and E X100)

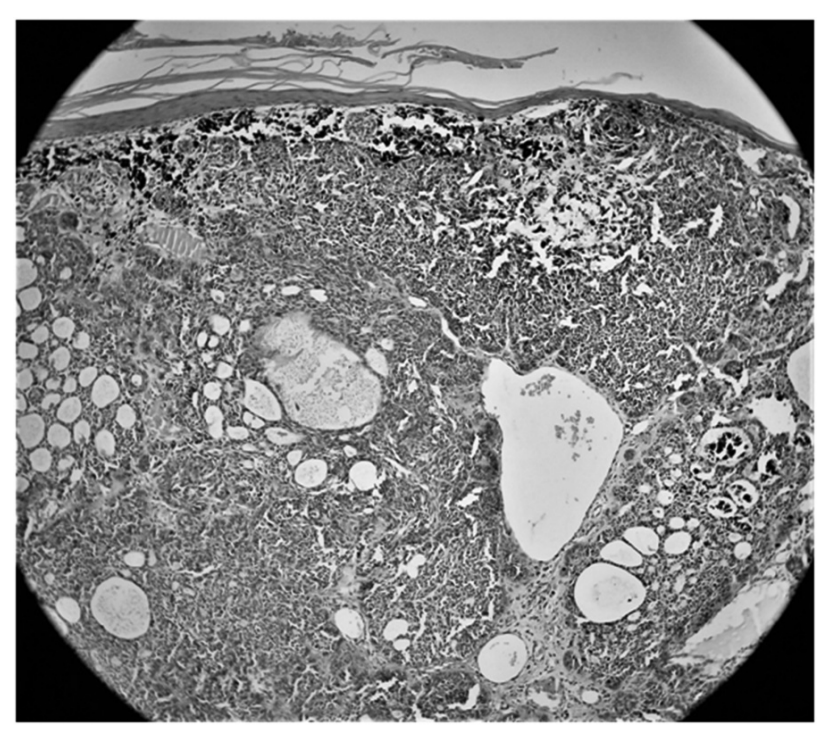

Figure 7. Trichoblastic carcinoma (H and E X100)

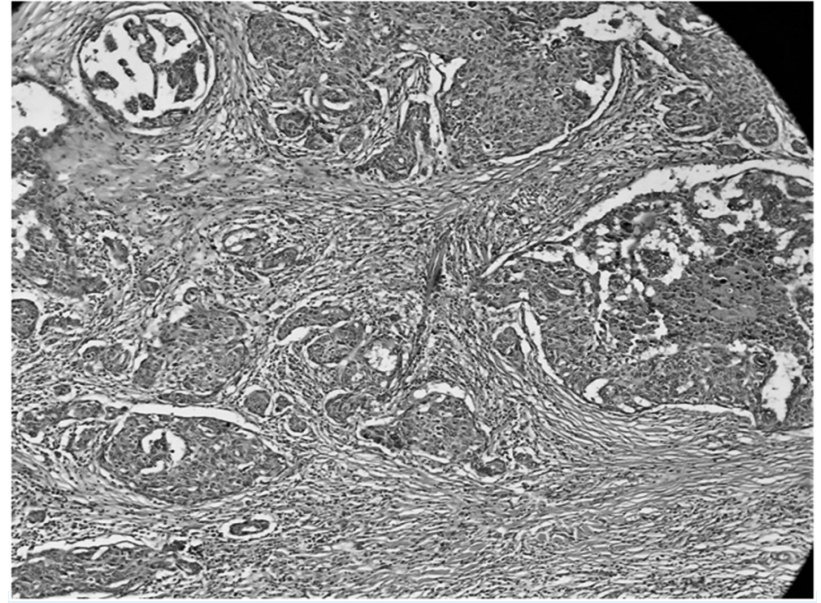

Figure 8. Hemorrhage within a tumor cluster in basaloid squamous cell carcinoma ( $\mathrm{H}$ and $\mathrm{E} \times 100)$

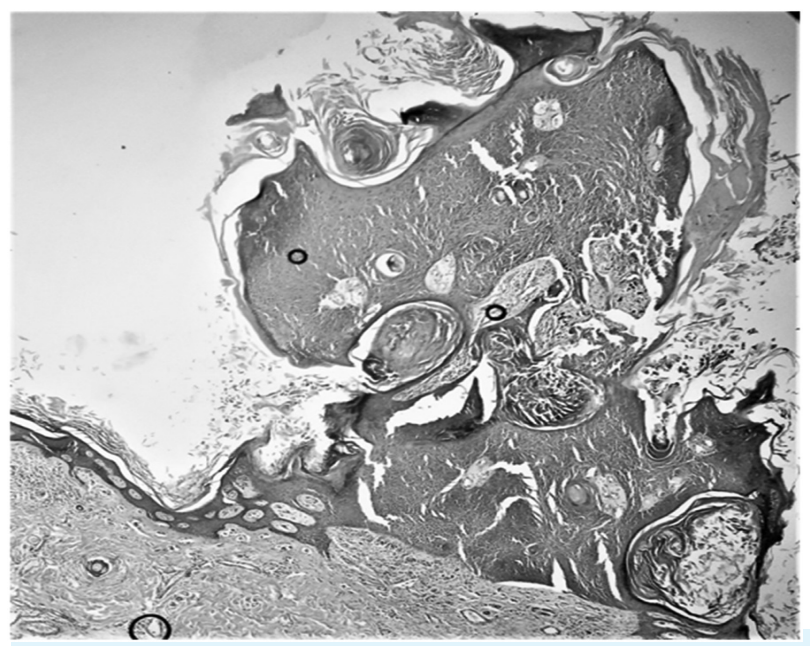

Figure 9. Pigmented Seborrhoeic keratosis (H and E X40)

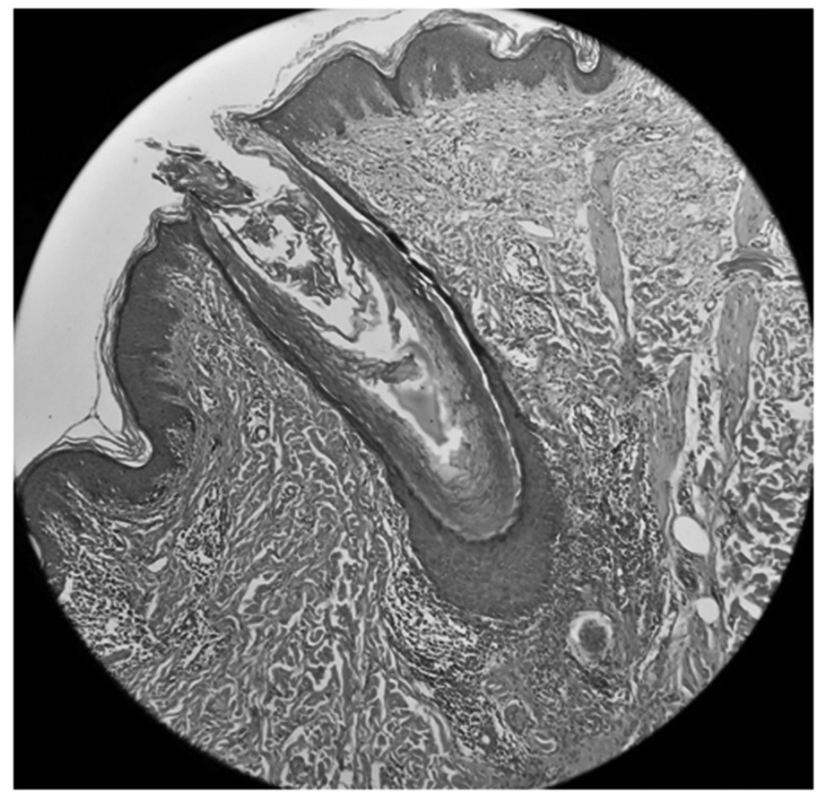

Figure 10. Interface dermatitis at the base of hypertrophied rete peg in lichen planus hypertrophicus ( $\mathrm{H}$ and $\mathrm{EX} 100$ ) 
In 29 (67.4\%) cases, histopathological diagnosis agreed with clinical diagnosis (Table 4). In $3(7.0 \%)$ cases, histopathological diagnosis agreed with differential diagnosis. Combined, clinicopathological agreement could be seen in $32(74.4 \%)$ cases. However, in 11 (25.6\%) cases, histopathological diagnosis did not agree with clinical diagnosis. Moreover, malignancy was clinically suspected in only $3(7.0 \%)$ cases, whereas, it was histopathologically seen in 6 $(14.0 \%)$ cases.

\section{DISCUSSION}

Pigmented skin lesions are one of the most frequent causes of dermatologic consultation. ${ }^{2}$ They are a heterogeneous group based on etiology, underlying pathology and nature of pigment. Hyperpigmentation may be epidermal or dermal. ${ }^{6}$ Pigmented skin lesions can mimic melanocytic lesions including melanoma. Such mimickers may be seborrheic keratosis, pigmented $\mathrm{BCC}$, actinic keratosis,

Table 4. Comparison between clinical and histopathological diagnosis.

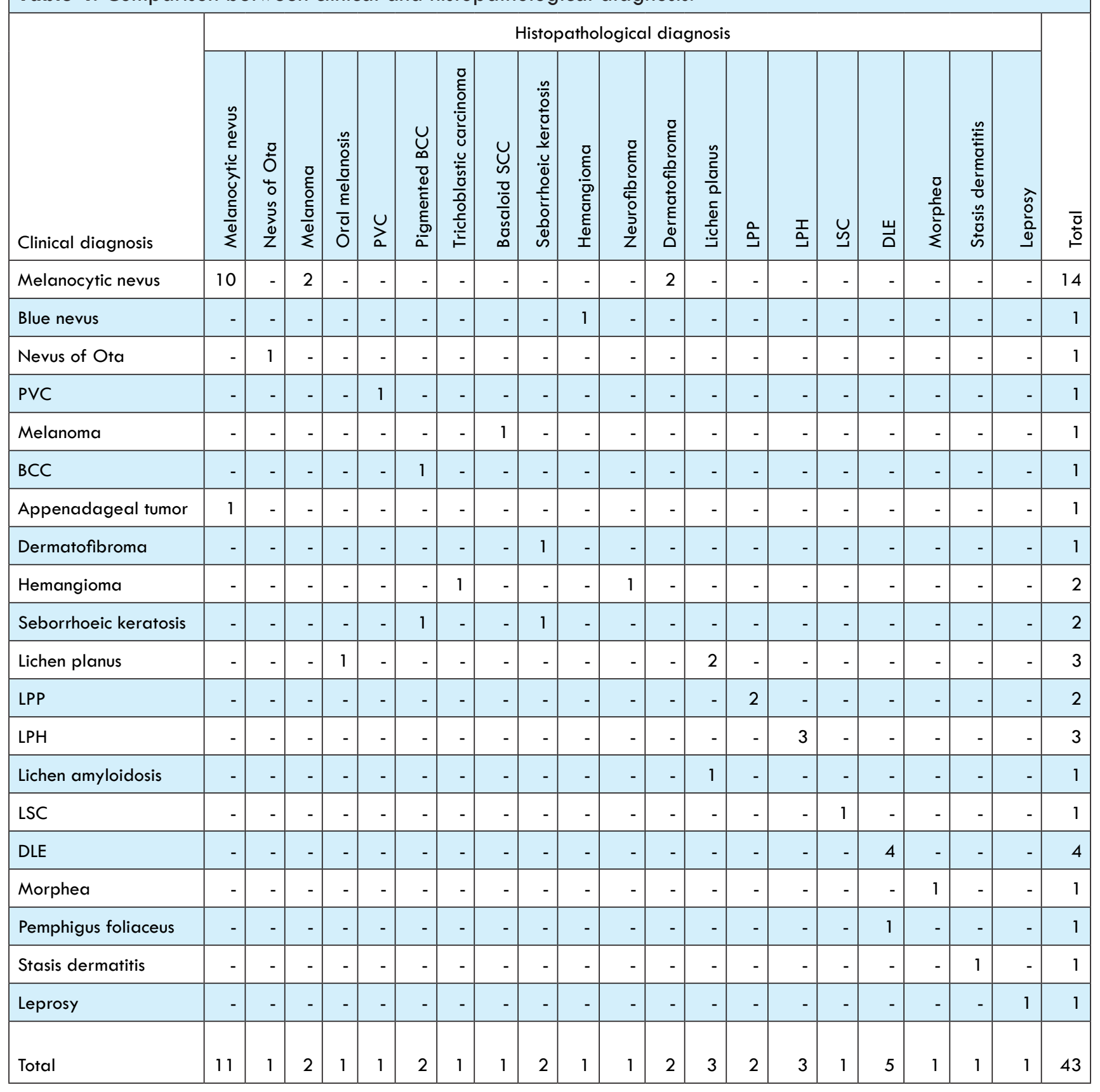


dermatofibrosarcoma protuberance and rarely lesions like follicular cyst. ${ }^{4}$

Age of the patient ranged from 1- to 88 years and mean \pm SD was $42 .-2 \pm 19.73$ years which was similar to findings of Laishram et al. where pigmented skin lesions occurred over a wide age range. ${ }^{4}$ Males and females were roughly equally affected in the present study. However, in studies conducted by Laishram et al. and Leung et al., female patients were seen considerably more in number. ${ }^{4} 5$ Face was the most common site in studies done by Laishram et al. and Crasta et al. ${ }^{4}$ ${ }^{7}$ However, extremities were the most common site with face being second most common site in the present study.

Melanocytic nevus was the most common histopathological diagnosis accounting for $25.6 \%$ of cases. Also in studies conducted by Laishram et al. and Dowerah et al., melanocytic nevi were most common, but comprised for higher $74.4 \%$ and 6-\% cases respectively. ${ }^{4,8}$

Lichenoid tissue reactions including lichen planus, lichen planus hypertrophicus, lichen planus pigmentosus and lichen simplex chronicus comprised a significant $21 \%$ cases. Interface dermatitis in these conditions often result in loss of melanin from basal cells which are ingested by melanophages and result in pigmentary changes. ${ }^{9}$ Lichenoid tissue reactions were most common cause of pigmentation in study conducted by Mruthyunjayappa et al., however, the authors had excluded neoplastic, infectious and developmental etiologies of pigmentation. ${ }^{2}$ Interface dermatitis occurring in these disorders is also an important cause of increased pigmentation and should be considered in differential diagnoses.

Seborrheic keratosis comprised $6 \%$ and $13 \%$ cases respectively in studies done by Laishram et al. and Dowerah et al. ${ }^{4,8}$ In the present study, it was seen in $4.7 \%$ cases only.
Malignant cases comprised $14 \%$ cases in the present study which was similar to findings of Laishram et al. where malignancy was seen in $13.7 \%$ cases. $^{4}$ In study done by Dowerah et al., malignancy was seen in $24 \%$ cases. ${ }^{8}$ However, much lower percentage of $1 \%$ malignancy was seen in study done by Leung et al. ${ }^{5}$ This may be due to regional variation in incidences of pigmented malignant tumors. Melanoma was histopathologically diagnosed in $4.7 \%$ cases of pigmented lesions in the present study. In study conducted by Laisharam et al. melanoma comprised $9.8 \%$ cases and in study conducted by Dowerah et al., it comprised $16 \%$ of pigmented lesions., 8 Melanoma is an uncommon tumor and it comprised only $-.94 \%$ of new cases and had 5 year prevalence $1.78 \%$ in Nepal according to Globocan 2-18. ${ }^{10}$ Other malignant tumors were pigmented basal cell carcinoma, pigmented basaloid sqaumous cell carcinoma and trichoblastic carcinoma in present study. In studies done by Laishram et al., Dowerah et al. and Leung et al., other malignant tumors showing pigmentation were cases of basal cell carcinoma. ${ }^{4,5,8}$

Malignancy was clinically not suspected in 7.-\% cases and moreover, 1 case clinically suspected as melanoma turned out to be basaloid variant of squamous cell carcinoma. In a study conducted in US, $2.3 \%$ of 1,946 specimens submitted as nevi turned out to be malignant. ${ }^{11}$ In present study, 2 out of $14(14.3 \%)$ cases clinically suspected as nevi turned out to be melanoma. In study conducted by Leung et al., 3.4\% and $-.5 \%$ of 816 cases clinically suspected as benign nevus turned out to be dysplastic nevus and malignancy respectively. ${ }^{5}$

Clinicopathological agreement was observed in $74.4 \%$ cases in present study. In studies done by Dowerah et al. and Mruthyunjayappa et al. clinicopathological agreement could be seen in $44 \%$ and $95 \%$ cases respectively. ${ }^{2,8}$ Integrated 
approach involving clinician and pathologist provides better management is some cases not only by confirming diagnosis but also by shifting from disease focused management to a patient centered approach. ${ }^{12}$

\section{CONCLUSIONS}

Melanocytic nevi were the most common pigmented lesions diagnosed. However, not all pigmented lesions are melanocytic in origin. Others like keratinocytic lesions, vascular lesions and reactive pigmentation in other conditions can also have pigmentation or appear pigmented. Malignant tumors can sometimes appear deceptively benign and also tumors other than melanoma can be pigmented. Hence, histopathological examination remains the gold

\section{REFERENCES}

1. Oakley A. Pigmented skin lesions [Internet]. [Hamilton]: New Zealand; 2-15. DermNet New Zealand; 2-15 October [cited 2-2- Jan 26]; [about 5 screens]. Available from: https://www. dermnetnz.org/topics/pigmented-skinlesions.html

2. Mruthyunjayappa S, Hemalata M, Gopal MG, Venugopal SB. A study of spectrum of histopathological features in patients presenting with hyperpigmented skin lesions. Archives of Medicine and Health Sciences. 2-16;4:189. DOI:1-.41-3/23214848.196195

3. Walter FM, Morris HC, Humphrys E, Hall PN, Kinmonth AL, Prevost AT, et al. Protocol for the MoleMate ${ }^{\mathrm{TM}} \mathrm{UK}$ Trial: a randomised controlled trial of the MoleMate system in the management of pigmented skin lesions in primary care [ISRCTN 79932379]. BMC Family standard in diagnosing these conditions and guiding appropriate management.

\section{ACKNOWLEDGEMENTS}

We are thankful to Department of Dermatology for sending biopsies and providing detailed clinical findings wherever necessary.

\section{Limitations}

This is a hospital based study. So, the results may not reflect upon entire population. Number of malignant cases was few. Larger sample size may give better results. The results are based on $\mathrm{H}$ and $\mathrm{E}$ stains only.

\section{Conflicts of interest:}

None declared.

Practice. 2-1-;11(1):36. doi: 1-.1186/14712296-11-36

4. Laishram RS, Myrthong B, Laishram S, Shimray R, K A, Sharma D. Pigmented Skin Lesions: Are They All Of Melanocytic Origin? A Histopathological Perspective. 2-13;23(3):284-8.

5. Leung KM, Chan KW. Pattern of pigmented skin tumours seen by private practitioners in Hong Kong. Hong Kong J Dermatol Venereol. 2--7;15:113-7.

6. Moscher DB, Fitzpatrick TB, Hori Y, Ortonne JP. Disorders of pigmentation. In: Fitzpatick TB, Isen AZ, Wolff K, Freedberg IM, Austen KF, editors. Dermatology in General Medicine. $4^{\text {th }}$ ed., New York: McGraw-Hill; 1993. p. 9-3-5.

7. Crasta J, Rameshkumar K. Pigmented lesions of nonmelanocytic origin- a pathological perspective. Indian J Dermatol. 2--2;47:84-7. 
8. Dowerah S, Deori R. A Histopathological Study of Pigmented lesions of Skin : Melanoma and its Clinical mimics. Global Journal for Reasearch Analysis. 2-17;6(11).

9. Sontheimer RD. Lichenoid Tissue Reaction/Interface Dermatitis: Clinical and Histological Perspectives. The Journal of investigative dermatology. 2-9;129:1-88-99. doi: 1-.1-38/sj.jid.2--9.42.

10. Bray F, Ferlay J, Soerjomataram I, Siegel RL, Torre LA, Jemal A. Global cancer statistics 2-18: GLOBOCAN estimates of incidence and mortality worldwide for
36 cancers in 185 countries. CA: a cancer journal for clinicians. 2-18;68(6):394-424. doi: 1-.3322/caac.21492.

11. Ahnlide I, Bjellerup M. Accuracy of Clinical Skin Tumour Diagnosis in a Dermatological Setting. Acta Dermato Venereologica, 2-13;93(3):3-5-3-8. doi. org/1-.234-/---15555-156-.

12. Longo C, Piana S, Lallas A, Moscarella E, Lombardi M, Raucci M, et al. Routine Clinical-Pathologic Correlation of Pigmented Skin Tumors Can Influence Patient Management. PloS one. 2-15;1(9):e-136-31. doi.org/1-.1371/journal. pone.-136-31.

Citation: Goyal B, Rai S, Sedhain M, Subedi P. Pigmented Lesions of Skin: A Histopathologic Experience at a Tertiary Care Center in Central Nepal. JCMS Nepal. $2021 ; 17(1) ; 1-9$. 